\title{
Resolved of Respiratory Failure Following the Use Pulse-Doses of Methylprednisolone in a Cytokine Storm Related to 2019 novel coronavirus
}

\author{
Hamid Khederlou$^{1}$, Abdolrahman Rostamian ${ }^{2 *}$, Elham Nezhadseifi ${ }^{2}$, Hourvash Ebrahimi-louyeh ${ }^{2}$ \\ ${ }^{1}$ Tehran Heart Center, Tehran University of Medical Sciences, Tehran, Iran. ${ }^{2}$ Rheumatology Department, Imam \\ Khomeini Hospital, Tehran University of Medical Sciences, Tehran, Iran.
}

\begin{abstract}
Since mid-December of 2019, an outbreak of pneumonia has been spread from Wuhan City, Hubei province, China, as a viral pneumonia. After virus identification and isolation, the pathogen for this pneumonia was originally called 2019 novel coronavirus (2019-nCoV). 2019-nCoV has been associated with progressive cytokine storm leading to a hyper-inflammatory state that this state associated with respiratory failure. We hereby reported a known case of Rheumatoid arthritis, Hypertension and Coronary artery bypass graft that confirmed $2019-\mathrm{nCoV}$ and he was associated with progressive cytokine storm leading to respiratory failure. After corticosteroid administration, respiratory failure and extremely high levels of IL6 responded dramatically to pulse-doses of Methylprednisolone. We concluded that pulse-doses of Corticosteroids can be effective in controlling and relieving cytokine storms and related respiratory failure.
\end{abstract}

Keywords: Cytokine storm, Interleukin-6, 2019 Novel coronavirus, Respiratory failure, Systemic corticosteroid

\section{Introduction}

Coronaviruses are enveloped RNA viruses of the family coronaviridae and broadly distributed in mammals such as humans [1]. Over the past two decades, viruses from this family have caused acute respiratory syndromes, such as severe acute respiratory syndrome coronavirus (SARS$\mathrm{CoV}$ ) and Middle East respiratory syndrome coronavirus (MERS-CoV), in more than 10,000 people $[2,3]$.

In mid-December of 2019, an outbreak of viral pneumonia began to spread from Wuhan city, Hubei province, China. After identification and isolation of the virus, the pathogen for this pneumonia was originally called the 2019 novel coronavirus (2019-nCoV) [4]. The most common manifestations of 2019-nCoV include fever, nonproductive cough, myalgia, fatigue, malaise, diarrhea, dyspnea, and hemoptysis [1]. While most human coronavirus infections are mild, 2019-nCoV can cause severe life-threatening complications, including acute respiratory distress syndrome, pneumonia, myocarditis, and organ failure [5]. The most common life-threatening complication of 2019-nCoV is respiratory failure [6]. 2019-nCoV has been associated with progressive cytokine storm leading to a hyper-inflammatory state associated with respiratory failure. Interleukin-6 (IL6) is a mediator of cytokine storm-related organ dysfunction and is strongly associated with severity and organ failure in 2019-nCoV $[7,8]$.

Because of the global concern about the 2019-nCoV pandemic and the related mortality rates, many attempts have been made to treat and control the virus, but they have had little or no effect

\section{Case Presentation}

A 51-year-old man referred to the emergency department of Imam Khomeini Hospital with nonproductive cough, progressive dyspnea, and chest discomfort that had begun three days earlier. He also complained of nausea, fever, myalgia, fatigue, and malaise. The patient had been diagnosed with rheumatoid arthritis 13 years earlier and treated with hydroxychloroquine (200 $\mathrm{mg}$, daily) and prednisolone (2.5 $\mathrm{mg}$, daily). He also had an 8-year history of hypertension and had undergone coronary artery bypass graft $(\mathrm{CABG}) 4$ years prior to this case. The patient was being treated with ASA $(80 \mathrm{mg}$, daily), atorvastatin (40 $\mathrm{mg}$, daily), nitrocantin $(2.6 \mathrm{mg}$,

Personal non-commercial use only. Rheumatology Research Journal. Copyright (C 2020. All rights reserved

*Corresponding Author: Dr Abdolrahman Rostamian. Associate Professor of Rheumatology, Rheumatology Department, Imam Khomeini Hospital, Tehran University of Medical Sciences, Tehran, Iran. E_mail: arostamian@tums.ac.ir. Phon: +98-912-333-7858.Received: 04 May 2020; Accepted: 22 June 2020 
every 12 hours), losartan (25 mg, every 12 hours), and amilodipine ( $5 \mathrm{mg}$, daily). On initial examination, he had an elevated blood pressure of $155 / 95 \mathrm{~mm} \mathrm{Hg}$, regular tachycardia at 114 beats per minute, respiratory rate of 26 breaths per minute, and a pulse oximetric figure of $82 \%$.

His pulmonary and cardiac examinations were normal. The patient had first been referred to an outpatient general practitioner, and a chest computerized tomography scan (CT scan) was performed for him at an imaging center outside the hospital. Based on physical examination and chest CT scan findings, he was then referred to the hospital. Bilateral ground glass opacities and sub-segmental areas of patchy consolidation were evident on the patient's CT scan (Figure 1). Based on the patient's respiratory distress, low SPO2, and chest CT scan findings, he was hospitalized and initial supportive treatment (e.g., oxygen therapy) was begun. Hydroxychloroquine and atazanavir were also prescribed for him.

Initial investigations, serum IL6 levels, and routine bacterial and sepsis work-ups were also performed. The diagnosis of 2019-nCoV was confirmed by pancoronavirus conventional polymerase chain reaction assay and sequencing of the polymerase chain reaction (PCR) amplicons using respiratory specimens, including nasal and pharyngeal swabs. Initial IL6 serum levels of 1162 $\mathrm{Pg} / \mathrm{ml}$ were detected. The results of other investigations are presented in Table 1.

After 5 days of hospitalization, the patient continued to have dyspnea with low Sat O2, tachypnea, and tachycardia as well as high ESR, CRP, and leukopenia in laboratory testing. Cytokine storm syndrome with respiratory failure was diagnosed; no response to treatment was noted after five days of hospitalization, so pulse-doses of methylprednisolone at $260 \mathrm{mg}$ daily were prescribed for three days, and the patient's general condition improved significantly. The PSO2 increased $87 \%$ and $91 \%$, respectively, on days 2 and 5 of methylprednisolone treatment, and his respiratory distress was resolved. Serum IL6 levels also decreased to less than $10 \mathrm{Pg} / \mathrm{ml}$. Serial vital signs are presented in Table 1.

Finally, the patient was discharged in good general condition, stable hemodynamic status, and with a PSO2 of $94 \%$ after 14 days of hospitalization (11 days in intensive care and 3 days in the ward).
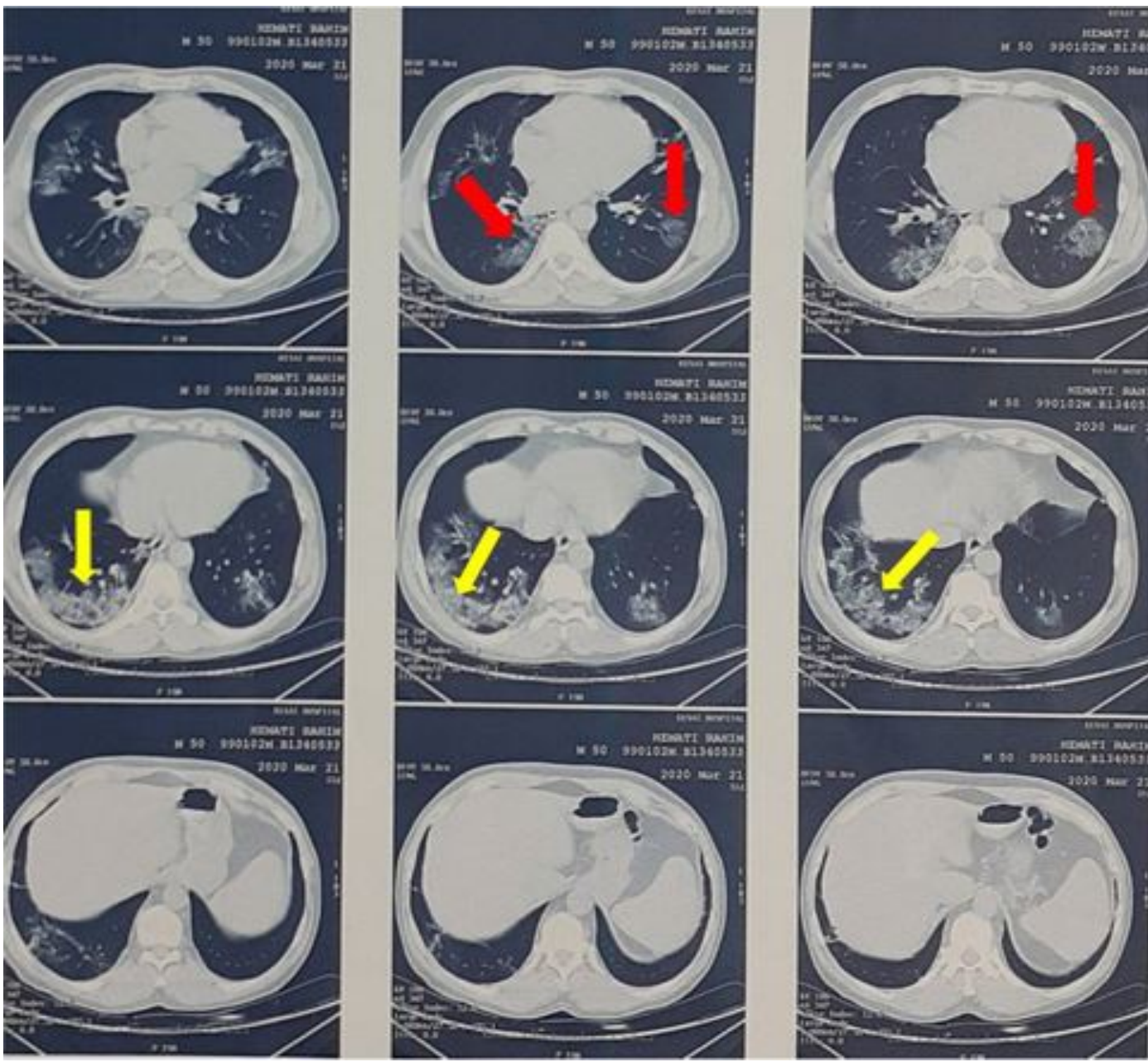

Figure 1. Axial images from chest CT scan

Bilateral involvement as ground glass opacities (Red arrow) and subsegmental areas of patchy consoldation (Yellow arrow). 
Table 1. Serial laboratory results and vital sign of the patient with 2019-nCoV

\begin{tabular}{|c|c|c|c|c|c|c|c|}
\hline Variables & HD $^{1} 1$ & HD 3 & HD 5* & HD 7 & HD 9 & HD 11 & HD 14 \\
\hline White blood cell count, $\times 10^{3} / \mu \mathrm{L}$ & 2900 & 2500 & 2400 & 2600 & 3200 & 3100 & 3400 \\
\hline Segment neutrophil, \% & 61.1 & 63.2 & 53.3 & 64.3 & 56.8 & 57.5 & 62.1 \\
\hline Lymphocyte, $\%$ & 24.5 & 26.0 & 35.5 & 25.1 & 31.9 & 28.4 & 24.4 \\
\hline Monocyte, $\%$ & 12.5 & 9.1 & 9.6 & 9.7 & 9.2 & 11.5 & 10.9 \\
\hline Eosinophil, \% & 0.9 & 0.3 & 0.8 & 0.6 & 0.8 & 1.3 & 1.3 \\
\hline Hemoglobin, g/dL & 15.4 & 15.1 & 15.3 & 14.8 & 14.2 & 14.7 & 14.4 \\
\hline Platelets, $\times 10^{3} / \mu \mathrm{L}$ & 221 & 182 & 208 & 221 & 252 & 198 & 187 \\
\hline Glucose, $\mathrm{mg} / \mathrm{dL}$ & 101 & 109 & 98 & 118 & 111 & 114 & 95 \\
\hline $\mathrm{BUN}^{2}, \mathrm{mg} / \mathrm{dL}$ & 14.4 & 12.6 & 14.1 & 9.1 & 9.8 & 10.4 & 7.8 \\
\hline Creatinine, $\mathrm{mg} / \mathrm{dL}$ & 1.1 & 1.4 & 1.3 & 1.3 & 1.0 & 1.0 & 0.8 \\
\hline Total bilirubin, $\mathrm{mg} / \mathrm{dL}$ & 0.56 & 0.59 & - & 0.46 & - & 0.64 & - \\
\hline $\mathrm{AST}^{3}, \mathrm{U} / \mathrm{L}$ & 31 & 29 & - & 25 & - & 19 & - \\
\hline $\mathrm{ALT}^{4}, \mathrm{U} / \mathrm{L}$ & 36 & 37 & - & 28 & - & 53 & - \\
\hline $\mathrm{ALP}^{5}, \mathrm{U} / \mathrm{L}$ & 7.9 & 158 & - & 14 & - & 113 & - \\
\hline Uric acid, mg/dL & 7.9 & - & - & - & - & - & - \\
\hline $\mathrm{LDH}^{6}, \mathrm{U} / \mathrm{L}$ & - & 332 & - & - & - & - & 351 \\
\hline Sodium, $\mathrm{mmol} / \mathrm{L}$ & 139 & 134 & 139 & 137 & 144 & 149 & 142 \\
\hline Potassium, mmol/L & 4.2 & 4.1 & 4.8 & 4.2 & 4.2 & 4.3 & 4.2 \\
\hline Total protein, $\mathrm{g} / \mathrm{dL}$ & 6.9 & - & - & - & 6.3 & - & 6.7 \\
\hline Albumin, $\mathrm{g} / \mathrm{dL}$ & 4.3 & - & - & - & 3.8 & - & 4.2 \\
\hline $\mathrm{ESR}^{7}, \mathrm{~mm} / \mathrm{hr}$ & 87 & - & 106 & - & 54 & - & 34 \\
\hline $\mathrm{CRP}^{8}, \mathrm{mg} / \mathrm{dL}$ & 184 & - & 204 & - & 106 & - & 57 \\
\hline Pro-Calcitonin, $\mathrm{ng} / \mathrm{mL}$ & 5.7 & - & - & - & - & - & - \\
\hline Prothrombin time (PT), sec & 13.5 & - & - & - & - & - & - \\
\hline international normalized ratio (INR) & 1.13 & - & - & - & - & - & - \\
\hline $\begin{array}{l}\text { activated partial thromboplastin time } \\
\text { (aPTT), sec }\end{array}$ & 39.6 & - & - & - & - & - & - \\
\hline NT-proBNP ${ }^{9}$ & - & - & - & 87.6 & - & - & - \\
\hline
\end{tabular}




\begin{tabular}{|c|c|c|c|c|c|c|c|}
\hline Variables & HD $^{1} 1$ & HD 3 & HD 5* & HD 7 & HD 9 & HD 11 & HD 14 \\
\hline Interleukin- $6, \mathrm{pg} / \mathrm{ml}$ & - & 1162 & & & & $<10$ & \\
\hline Blood pressure, $\mathrm{mm} \mathrm{Hg}$ & $155 / 95$ & $148 / 95$ & $128 / 92$ & $142 / 88$ & $138 / 90$ & $130 / 88$ & $132 / 86$ \\
\hline Pulse rate, beats per minute & 114 & 108 & 112 & 108 & 102 & 92 & 94 \\
\hline Respiratory rate, breaths per minute & 26 & 25 & 26 & 24 & 20 & 21 & 18 \\
\hline Saturation of $\mathrm{PO} 2$ & $82 \%$ & $81 \%$ & $83 \%$ & $87 \%$ & $90 \%$ & $91 \%$ & $94 \%$ \\
\hline
\end{tabular}

1. HD; Hospitalized day, 2. BUN; Blood urea nitrogen, 3. AST; aspartate aminotransferase, 4. ALT; alanine aminotransferase, 5. ALP; alkaline phosphatase, 6. LDH; Lactate dehydrogenase, 7. ESR; erythrocyte sedimentation rate, 8. CRP; C-reactive protein, 9. NT-proBNP; N-terminal pro b-type natriuretic peptide

* The start day of methylprednisolone administration

\section{Discussion}

Herein is reported a case of 2019-nCoV associated with progressive cytokine storm leading to respiratory failure which, along with extremely high levels of IL6, responded dramatically to corticosteroid pulses.

The most common complication and the leading cause of mortality in 2019-nCoV is lung injury [9], as seen in this reported case. Some evidence-based studies suggest that severe 2019-nCoV increases pro-inflammatory cytokines following lung injury and can develop into hyperinflammation as a cytokine storm syndrome; respiratory failure occurs in about $50 \%$ of such cases [8]. In the current study, the patient's IL6 level was reported to be more than $1000 \mathrm{mg} / \mathrm{dl}$, which is significantly elevated and indicates a cytokine storm associated with respiratory failure. Given the estimated mortality rate of $3-7 \%$, there is an urgent need for an effective treatment for $2019 \mathrm{nCoV}$. Current challenges have promoted the advancement of novel therapeutics, including antiviral medications [10]. Since the outbreak of 2019-nCoV, various medications have been used by physicians to reduce and control 2019-nCoVrelated lung injury, including hydroxychloroquine, lopinavir/ritonavir (Kaletra, AbbVie), interferon beta, ribavirin, and remdesivir [11].

Although the current literature on patients with influenza, SARS, or MERS suggests that receiving systemic corticosteroids has no effect on patient outcome and is even reported to delay viral clearance [12,13], some studies have reported the incidence of complications being higher in patients using systemic corticosteroids than in patients who did not [5]; however, corticosteroids were used frequently in SARS-CoV and MERS-CoV patients for the treatment of severe complications because of their possible advantages, such as reducing lung injury [13].

The use of corticosteroids in 2019-nCoV has now become a major challenge for clinicians, as some studies support its use [8] and some have found that their use increases mortality [14]. During the 2019-nCoV epidemic, corticosteroids have not been recommended according to the World Health Organization's (WHO) provisional guidance and insufficient experience with SARS-CoV and MERS-CoV epidemics [14, 15]. However, in hyperinflammation following cytokine storm syndrome, the use of corticosteroids might reduce the rising mortality rates [8]. As mentioned, the current case also responded dramatically to systemic corticosteroids.

\section{Conclusion}

As 2019-nCoV is a global health threat, appropriate actions against it, especially appropriate treatments, are needed. In general, more evidence-based information and findings are needed to determine whether systemic corticosteroid therapy is beneficial or harmful to 2019-nCoV infected patients.

\section{Conflict of interest}

None. 
1. Chan JF, Yuan S, Kok KH, To KKW, Chu H, Yang J. et al. A familial cluster of pneumonia associated with the 2019 novel coronavirus indicating personto-person transmission: a study of a family cluster. Lancet 2020; 395(10223):514-23. doi.org/10.1016/S0140-6736(20)30154-9.

2. Yao TT, Qian JD, Zhu WY, Wang Y, Wang GQ. A systematic review of lopinavir therapy for SARS coronavirus and MERS coronavirus-A possible reference for coronavirus disease-19 treatment option. J Med Virol 2020; 92(6):556-63. doi: 10.1002/jmv.25729.

3. Groot RJ, Baker SC, Baric RS, Brown CS, Drosten $\mathrm{C}$, Enjuanes L. et al. Middle East respiratory syndrome coronavirus (MERS-CoV): announcement of the Coronavirus Study Group. $\boldsymbol{J}$ Virol 2013; 87(14):7790-92. doi: 10.1128/JVI.01244-13.

4. Yang Z, Liu J, Zhou Y, Zhao X, Zhao Q, Liu J. The effect of corticosteroid treatment on patients with coronavirus infection: a systematic review and meta-analysis. J Infect 2020; 81(1):e13-e20. doi: 10.1016/j.jinf.2020.03.062.

5. Huang C, Wang Y, Li X, Ren L, Zhao J, Hu Y. et al. Clinical features of patients infected with 2019 novel coronavirus in Wuhan, China. Lancet 2020; 395(10223):497-06. doi.org/10.1016/S01406736(20)30183-5.

6. Xu XW, Wu XX, Jiang XG, Xu KJ, Ying LJ, Ma CL. et al. Clinical findings in a group of patients infected with the 2019 novel coronavirus (SARSCov-2) outside of Wuhan, China: retrospective case series. BMJ 2020; 368:m606. doi: 10.1136/bmj.m606.

7. Chen C, Zhang XR, Ju ZY, He WF. Advances in the research of cytokine storm mechanism induced by Corona Virus Disease 2019 and the corresponding immunotherapies. Zhonghua Shao Shang Za Zhi. 2020; 36(6):471-75. doi: 10.3760/cma.j.cn50112020200224-00088.
8. Mehta P, McAuley DF, Brown M, Sanchez E, Tattersall RS, Manson JJ. et al. COVID-19: consider cytokine storm syndromes and immunosuppression. Lancet 2020; 395(10229):1033-34. doi: 10.1016/S01406736(20)30628-0.

9. Chen N, Zhou M, Dong X, Qu J, Gong F, Han Y. et al. Epidemiological and clinical characteristics of 99 cases of 2019 novel coronavirus pneumonia in Wuhan, China: a descriptive study. Lancet 2020; 395(10223):507-13. doi: 10.1016/S01406736(20)30211-7.

10. Coronavirus disease 2019 (COVID-19) situation report - 52. [https://www.who.int/docs/defaultsource/coronaviruse/20200312-sitrep-52-covid19.pdf?sfvrsn $\left.=\mathrm{e} 2 \mathrm{bfc} 9 \mathrm{c} 0 \_2\right]$.

11. Prajapat M, Sarma P, Shekhar N, Avti P, Sinha S, Kaur H. et al. Drug targets for corona virus: A systematic review. Indian J Pharmacol 2020; 52(1):56-65. doi: 10.4103/ijp.IJP_115_20.

12. Falzarano D, de-Wit E, Rasmussen AL, Feldmann F, Okumura, A, Scott DP. et al. Treatment with interferon- $\alpha 2 b$ and ribavirin improves outcome in MERS-CoV-infected rhesus macaques. Nat Med 2013; 19(10):1313-17. doi: 10.1038/nm.3362.

13. Lansbury L, Rodrigo C, Leonardi-Bee J, NguyenVan-Tam J, Lim WS. Corticosteroids as adjunctive therapy in the treatment of influenza. Cochrane Database Syst Rev 2019; 2(2): CD010406. doi: 10.1002/14651858.CD010406.pub3.

14. Russell CD, Millar JE, Baillie JK. Clinical evidence does not support corticosteroid treatment for 2019nCoV lung injury. Lancet 2020; 395(10223):47375. doi: 10.1016/S0140-6736(20)30317-2.

15. Clinical management of severe acute respiratory infection when novel coronavirus (nCoV) infection is suspected. [https://www.who.int/internalpublications-detail/clinical-management-ofsevere-acute-respiratory-infection-when-novelcoronavirus-(ncov)-infection-is-suspected] 